\title{
Changes in the Concentrations of Mediators of Inflammation and Oxidative Stress in Exhaled Breath Condensate During Liver Transplantation and Their Relations With Postoperative ARDS
}

\author{
Dezhao Liu MD, Gangjian Luo MD, Chenfang Luo MD, Tao Wang MD, Guoliang Sun MD, \\ and Ziqing Hei PhD
}

\begin{abstract}
BACKGROUND: Oxidative stress and inflammatory responses are thought to be involved in the pathogenesis of ARDS, which is one of the most serious complications of orthotopic liver transplantation (OLT). The collection of exhaled breath condensate (EBC) is a noninvasive method for obtaining clinical samples from the lungs. However, the changes of mediators of inflammation and oxidative stress in EBC remain unclear. Therefore, the aim of this study was to investigate the changes of mediators in EBC from OLT subjects and the relations between these mediators and ARDS. METHODS: The levels of mediators of oxidative stress (superoxide dismutase [SOD], malondialdehyde [MDA] $\mathrm{H}_{2} \mathrm{O}_{2}$, NO, and 8-iso-prostaglandin $\mathrm{F}_{2 \alpha}$ ) and of inflammatory factors (tumor necrosis factor- $\alpha$ [TNF- $\alpha$ ], interleukin [IL]-8, and IL-10) were measured in EBC and serum samples collected from 28 subjects before OLT surgery and at 2 and $4 \mathrm{~h}$ after the anhepatic phase. The diagnostic value for ARDS until the 3 days following transplantation was evaluated. RESULTS: Eighteen subjects developed ARDS after OLT. The concentrations of TNF- $\alpha$, IL-8, MDA, NO, $\mathrm{H}_{2} \mathrm{O}_{2}$, and 8-iso-prostaglandin $\mathrm{F}_{2 \alpha}$ were much higher in the ARDS group than in the control group, whereas the levels of IL-10 and SOD were lower in the ARDS group than in the control group. The serum levels of mediators of oxidative stress or inflammation were closely related to EBC levels. Receiver operating characteristic analysis showed that areas under the curves for $\mathrm{MDA}, \mathrm{NO}, \mathrm{H}_{2} \mathrm{O}_{2}$, 8-iso-prostaglandin $\mathrm{F}_{2 \alpha}$, TNF- $\alpha$, IL-8, SOD, and IL-10 were $0.88,0.88,0.78,0.84,0.84,0.94,0.81$, and 0.84 at $2 \mathrm{~h}$ after graft reperfusion and $0.98,0.88,0.92,0.79,0.95,0.83,0.88$, and 0.97 at $4 \mathrm{~h}$ after graft reperfusion. CONCLUSIONS: EBC analysis is a noninvasive method for detecting mediators of inflammation and oxidative stress from the lungs. This method could be used to predict the higher incidence of ARDS induced by OLT. Key words: exhaled breath condensate; orthotopic liver transplantation; ARDS. [Respir Care 2015;60(5):679-688. (C) 2015 Daedalus Enterprises]
\end{abstract}

\section{Introduction}

ARDS is a common complication of orthotopic liver transplantation (OLT) and has high morbidity and mortal-

Drs Liu, G Luo, C Luo, Hei, and Sun are affiliated with the Department of Anesthesiology, Third Affiliated Hospital of Sun Yat-sen University, Guangzhou City, People's Republic of China. Dr Wang is affiliated with the Department of Cardiothoracic Surgery, Longgang People's Hospital, Shenzhen City, People's Republic of China.

Drs Liu and G Luo are co-first authors of this paper.

This study was supported by grant 2011B031800058 from the Scientific and Technological Project Foundation of Guangdong Province (People's ity rates. ${ }^{1}$ However, the diagnosis of ARDS is indirect and based on arterial blood gas measurements, bronchial la-

\footnotetext{
Republic of China), grant 82000-3281901 from the 985 Project of China, and grant 2011B0929 from the Braun Scientific Research Fund for Anesthesia.

The authors have declared no conflicts of interest.

Correspondence: Ziqing Hei PhD, Department of Anesthesiology, Third Affiliated Hospital of Sun Yat-sen University, No. 600 Tianhe Road, Tianhe District, Guangzhou City 510630, People's Republic of China. E-mail: heiziqing@sina.com.
}

DOI: $10.4187 /$ respcare. 03311 


\section{Exhaled Breath Condensate Biomarkers and Postoperative ARDS}

vage fluid analysis, and chest x-ray findings, which are considered to lag behind the clinical picture, such as increasing respiratory distress and tachycardia. ${ }^{2}$ A new, noninvasive method for the early prediction of ARDS induced by OLT is urgently needed.

Much pulmonary research over the past several decades has focused on noninvasive methods for detecting biochemical markers in the airway. One such method involves the collection of exhaled breath condensate (EBC). ${ }^{3}$ $\mathrm{EBC}$ analysis is a relatively new technique for exploring the role of inflammation in respiratory diseases that is convenient and also avoids lung injury. However, whether the molecules measured in EBC are associated with pulmonary inflammation or oxidative stress remains unclear. ${ }^{4}$

Although it is known that inflammatory responses and oxidative stress are primarily responsible for ARDS, measurements of mediators of inflammation and oxidative stress during liver transplantation have been neglected. ${ }^{5,6}$ Thus, we analyzed changes in the levels of these mediators in EBC and in serum from OLT subjects and investigated their relations with postoperative ARDS. We hypothesized that increases in the levels of inflammatory and oxidative mediators in EBC would predict an increased risk of postoperative ARDS after OLT.

\section{Methods}

\section{Subjects}

This study was approved by the Research Committee of the Third Affiliated Hospital of Sun Yat-Sen University, and informed consent was obtained from the legal caretaker of each participant (reference CHICTR-PNRC0800043). Twenty-eight adult subjects with end-stage cirrhosis (18 males and 10 females) with American Society of Anesthesiologists statuses of II-IV underwent modified piggyback liver transplantations. Among them, 14 had cirrhosis due to hepatitis B, 12 had cirrhosis with small liver cancer tumors, and 2 had primary biliary cirrhosis. Twelve subjects were categorized as Child's grade B, 10 subjects as grade $\mathrm{C}$, and 6 as grade $\mathrm{A}$. Two subjects had hepatic encephalopathy grade I, and one subject had hepatic encephalopathy grade II.

\section{Anesthesia and Intra-operative Management}

Subjects were placed under general anesthesia. Anesthesia was induced with propofol $(1-2 \mathrm{mg} / \mathrm{kg})$ and fentanyl $(5 \mu \mathrm{g} / \mathrm{kg})$ administered intravenously, and neuromuscular blockade was accomplished with cisatracurium $(0.1 \mathrm{mg} / \mathrm{kg}$, administered intravenously). Subjects were mechanically ventilated in a volume-controlled mode with an anesthesia ventilator (Datex-Ohmeda, Madison, Wisconsin). The ventilator settings consisted of a tidal volume

\section{QUICK LOOK}

\section{Current knowledge}

Oxidative stress and inflammatory response are implicated in the pathogenesis of ARDS. Exhaled breath condensate may be a noninvasive method for obtaining clinical samples from the lungs. To date, the presence and alterations of inflammatory mediators and markers of oxidative stress in exhaled breath condensate have not provided clinically relevant information.

\section{What this paper contributes to our knowledge}

In a small group of subjects developing ARDS following liver transplantation, analyses of exhaled breath condensate generated a noninvasive index to predict the risk of postoperative ARDS. The utility of these data in this and other populations to predict the development of ARDS requires further study.

$\left(\mathrm{V}_{\mathrm{T}}\right)$ of $8-10 \mathrm{~mL} / \mathrm{kg}$, a breathing frequency of $10-$ 14 breaths/min, and an inspiratory/expiratory ratio of 1.5 ; the end-tidal carbon dioxide $\mathrm{CO}_{2}$ tension was maintained between 30 and $35 \mathrm{~mm} \mathrm{Hg}$. The PEEP was set at $0 \mathrm{~cm}$ $\mathrm{H}_{2} \mathrm{O}$. The $\mathrm{V}_{\mathrm{T}}$ was not manipulated until $\mathrm{P}_{\mathrm{aO}_{2}}$ was below $300 \mathrm{~mm} \mathrm{Hg}$ and $\mathrm{S}_{\mathrm{pO}_{2}}$ was lower than $98 \%$. We adjusted the respiratory parameters, such as increasing of PEEP, decreasing the tidal volume, and increasing the oxygen concentration. General anesthesia was maintained with $1.0-3.5 \%$ sevoflurane in a mixture of $60 \%$ oxygen-air. After the induction of anesthesia, direct arterial pressure was monitored by the left radial artery, and a pulmonary artery catheter was then inserted to measure cardiac output. After OLT, subjects were transferred to the ICU, and mechanical ventilation was continued until successful extubation was achieved.

\section{Definitions of Each Perioperative Phase}

The anhepatic phase is the period from vascular clamping to reperfusion of the portal vein and the inferior vena cava, and the neohepatic phase is the period from reperfusion of the donor liver to the end of the operation.

\section{Monitoring of Respiratory Mechanics and Oxygenation}

Respiratory parameters, including the $\mathrm{V}_{\mathrm{T}}$, dynamic compliance, peak inspiratory pressure (PIP), breathing frequency, mean airway pressure, and plateau pressure, were measured. Some other oxygenation parameters, such as respiratory index (RI), $\mathrm{P}_{\mathrm{aO}_{2}} / \mathrm{F}_{\mathrm{IO}_{2}}$ ratio $(\mathrm{P} / \mathrm{F})$, and $\mathrm{P}_{(\mathrm{A}-\mathrm{a}) \mathrm{O}_{2}}$ 


\section{Exhaled Breath Condensate Biomarkers and Postoperative ARDS}

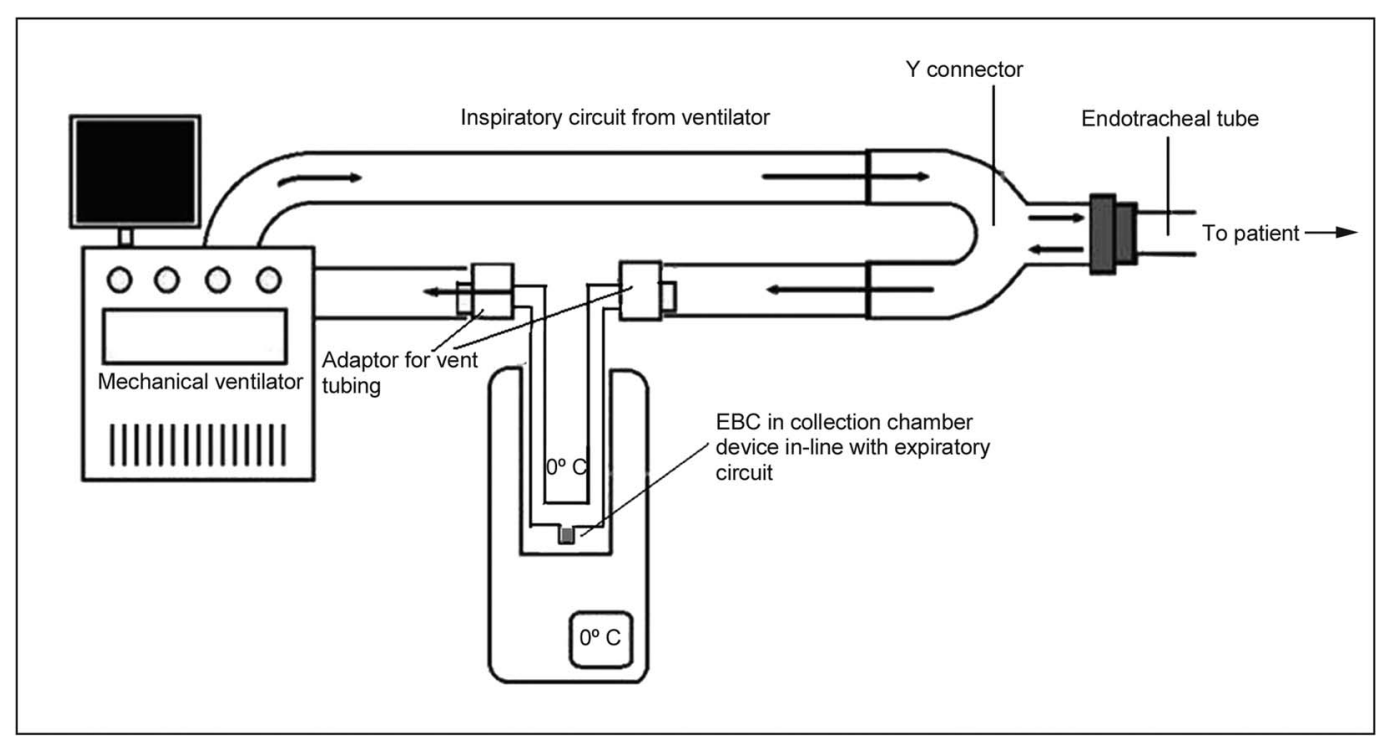

Fig. 1. The exhaled breath condensation (EBC) collection device consisted of a portable glass tube in line with the expiratory limb of the ventilator circuit. The glass tube was cooled with a mixture of ice and water surrounding the tube to generate temperatures reaching $0^{\circ} \mathrm{C}$.

were calculated according to the following formulas ${ }^{7}$ : $\mathrm{P} / \mathrm{F}=\mathrm{P}_{\mathrm{aO}_{2}} / \mathrm{F}_{\mathrm{IO}_{2}}, \mathrm{P}_{(\mathrm{A}-\mathrm{a}) \mathrm{O}_{2}}=\mathrm{P}_{\mathrm{AO}_{2}}-\mathrm{P}_{\mathrm{aO}_{2}}, \mathrm{P}_{\mathrm{AO}_{2}}=$ $\mathrm{P}_{\mathrm{IO}_{2}}-\left(1.25 \times \mathrm{P}_{\mathrm{aCO}_{2}}\right), \mathrm{P}_{\mathrm{IO}_{2}}=(760-47) \times \mathrm{F}_{\mathrm{IO}_{2}}$, and $\mathrm{RI}=\mathrm{P}_{(\mathrm{A}-\mathrm{a}) \mathrm{O}_{2}} / \mathrm{P}_{\mathrm{aO}_{2}}$.

\section{Collection of Exhaled Breath Condensate}

The EBC collection device was constructed using a portable glass tube in line with the expiratory limb of the ventilator circuit (Fig. 1). The glass tube was cooled by being surrounded with a mixture of ice and water to generate temperatures reaching $0^{\circ} \mathrm{C}$. Once the collection was finished, the glass tube was disconnected, and the sample was stored immediately at $-80^{\circ} \mathrm{C}$. The EBC samples were collected at four time points: $\mathrm{T}_{1}(5 \mathrm{~min}$ after induction of anesthesia), $\mathrm{T}_{2}$ (2 $\mathrm{h}$ after graft reperfusion), $\mathrm{T}_{3}(4 \mathrm{~h}$ after graft reperfusion), and $\mathrm{T}_{4}$ ( $24 \mathrm{~h}$ after graft reperfusion).

\section{Blood Sample Collection}

Radial artery blood samples $(4 \mathrm{~mL})$ were collected at $\mathrm{T}_{1}, \mathrm{~T}_{2}, \mathrm{~T}_{3}$, and $\mathrm{T}_{4}$ and divided into 2 aliquots. One aliquot ( $2 \mathrm{~mL}$ ) was promptly used for blood gas analysis, and the other $(2 \mathrm{~mL})$ was used for measurements of mediators of inflammation and oxidative stress.

\section{Assays for Mediators of Inflammation and Oxidative Stress}

All EBC and serum samples were divided into 2 aliquots. One set of EBC and serum aliquots was assayed for
TNF- $\alpha$, IL-8, IL-10, and 8-iso-prostaglandin $\mathrm{F}_{2 \alpha}$ using a commercially available enzyme-linked immunosorbent assay kit (R\&D Systems, Minneapolis, Minnesota) according to the manufacturer's instructions. The other set of EBC and serum aliquots was assayed for SOD, MDA, NO, and $\mathrm{H}_{2} \mathrm{O}_{2}$ using commercially available assays (Jiancheng Bioengineering, Nanjing, China) according to the manufacturer's instructions.

\section{Definitions of Outcome Variables}

Postoperative ARDS. Subjects were considered to have ARDS if they met the 2012 Berlin definition of ARDS definition, ${ }^{8}$ which required the development of ARDS within $3 \mathrm{~d}$ after OLT. ARDS was based on degree of hypoxemia: mild (200 mm Hg $<\mathrm{P}_{\mathrm{aO}_{2}} / \mathrm{F}_{\mathrm{IO}_{2}} \leq 300 \mathrm{~mm} \mathrm{Hg}$ ), moderate $\left(100 \mathrm{~mm} \mathrm{Hg}<\mathrm{P}_{\mathrm{aO}_{2}} / \mathrm{F}_{\mathrm{IO}_{2}} \leq 200 \mathrm{~mm} \mathrm{Hg}\right)$, and severe $\mathrm{P}_{\mathrm{aO}_{2}} / \mathrm{F}_{\mathrm{IO}_{2}} \leq 100 \mathrm{~mm} \mathrm{Hg}$ ). All subjects received the same therapies before experiencing ARDS, and standardized treatment was made for those who developed ARDS.

Postoperative Pulmonary Infection. Pulmonary infections that developed within $3 \mathrm{~d}$ after transplantation were recorded, but preoperative pulmonary infections were not recorded for this study.

Other Complications. Secondary outcome measures including the amount of bleeding, transfusion volume, time to extubation, in-hospital mortality rate, postoperative stay, and the stay in the ICU were all recorded. 


\section{Exhaled Breath Condensate Biomarkers and Postoperative ARDS}

Table 1. Characteristics and Outcomes of OLT Subjects

\begin{tabular}{|c|c|c|c|}
\hline Characteristics and Outcomes & $\begin{array}{l}\text { ARDS Group } \\
\quad(n=18)\end{array}$ & $\begin{array}{l}\text { Control Group } \\
\quad(n=10)\end{array}$ & $P$ \\
\hline Age (y) & $58.34 \pm 8.25$ & $57.93 \pm 7.96$ & .38 \\
\hline Sex (male/female) & $12 / 6$ & $6 / 4$ & .72 \\
\hline Weight $(\mathrm{kg})$ & $78.88 \pm 5.51$ & $75.50 \pm 6.35$ & .61 \\
\hline Height (cm) & $162.22 \pm 7.06$ & $164.33 \pm 8.64$ & .55 \\
\hline Duration of operation (min) & $411.67 \pm 40.21$ & $398.33 \pm 76.56$ & .20 \\
\hline Anhepatic time (min) & $39.94 \pm 7.53$ & $37.67 \pm 5.16$ & .50 \\
\hline Liver cold ischemia time (min) & $6.97 \pm 1.60$ & $6.00 \pm 1.18$ & .19 \\
\hline Child-Pugh score & $9.56 \pm 2.79$ & $14.89 \pm 3.58$ & .08 \\
\hline MELD score & $7.33 \pm 1.75$ & $11.67 \pm 3.11$ & .11 \\
\hline Mortality $(n, \%)$ & $0(0)$ & $0(0)$ & $>.99$ \\
\hline Ascites $(\mathrm{ml})$ & $834 \pm 258$ & $926 \pm 347$ & .14 \\
\hline Concentrated red blood cells $(\mathrm{mL})$ & $1085 \pm 782$ & $1247 \pm 753$ & .62 \\
\hline Fresh frozen plasma $(\mathrm{mL})$ & $2248 \pm 589$ & $2105 \pm 672$ & .75 \\
\hline Platelet $(\mathrm{mL})$ & $156 \pm 78$ & $134 \pm 85$ & .82 \\
\hline Cryoprecipitate (mL) & $924 \pm 281$ & $905 \pm 312$ & .63 \\
\hline Albumin $(\mathrm{mL})$ & $301 \pm 127$ & $286 \pm 137$ & .84 \\
\hline Intraoperative urine output & $861 \pm 346$ & $835 \pm 302$ & .59 \\
\hline Time to extubation (h) & $13.83 \pm 6.59$ & $8.83 \pm 4.10$ & .03 \\
\hline Postoperative pulmonary infection $(\%)$ & 6 & 0 & .04 \\
\hline Length of stay in ICU (d) & $8.68 \pm 3.49$ & $3.12 \pm 1.26$ & $<.001$ \\
\hline Postoperative length of stay (d) & $25.26 \pm 8.74$ & $18.33 \pm 6.28$ & .02 \\
\hline $\begin{array}{l}\text { MELD }=\text { model for end-stage liver disease } \\
\text { OLT }=\text { orthotopic liver transplantation }\end{array}$ & & & \\
\hline
\end{tabular}

\section{Statistical Analysis}

The chi-square test of independence was used to examine categorical variables, and independent sample $t$ tests were used to compare continuous characteristics between 2 groups. Areas under the curve were calculated from standard receiver operating characteristic plots. An area under the curve of 0.5 is no better than that expected by chance, whereas a value of 1.0 signifies a perfect biomarker. Relationships between the inflammatory or oxidative mediators in EBC and those in serum were analyzed using Pearson correlation coefficients. $P<.05$ was considered statistically significant. SPSS 16.0 (SPSS, Chicago, Illinois) was used to generate all statistical analyses and figures.

\section{Results}

\section{General State of Health}

All operations were successful. Among the 28 subjects who participated in this study, 18 subjects suffered from ARDS after OLT, including 9 cases with mild ARDS, 5 cases with moderate ARDS, and 4 cases with severe ARDS. No sepsis or gastric aspiration occurred in any of the 28 subjects. As shown in Table 1, no differences were ob- served between the 2 groups in regard to age, weight, sex, height, preoperative MELD (Model for End-stage Liver Disease) score, Child-Pugh score, ascites, concentrated red blood cells, fresh frozen plasma, platelet, albumin and cryoprecipitate, intra-operative urine output, anhepatic time, liver cold ischemia time, and duration of operation.

\section{Perioperative Respiratory Mechanics and Oxygenation Parameters}

Pulmonary function may be related to respiratory mechanics and oxygenation parameters. ${ }^{9}$ Thus, in the current study, we measured subjects' perioperative respiratory mechanics and oxygenation parameters, such as PIP, mean airway pressure, $\mathrm{P}_{(\mathrm{A}-\mathrm{a}) \mathrm{O}_{2}}, \mathrm{P} / \mathrm{F}$, and dynamic compliance. As shown in Figure 2, PIP, mean airway pressure, and $\mathrm{P}_{(\mathrm{A}-\mathrm{a}) \mathrm{O}_{2}}$ were significantly higher in the ARDS group at $\mathrm{T}_{2}$ and $\mathrm{T}_{3}$ compared with the control group (Fig. 2). However, there were no significant differences in $\mathrm{V}_{\mathrm{T}}$ at $\mathrm{T}_{2}$ and $\mathrm{T}_{3}$ between the ARDS group and the control group $(P=.25$; $0.18)$. In addition, $\mathrm{P} / \mathrm{F}$ and dynamic compliance were significantly lower at $T_{2}$ and $T_{3}$ compared with the control group (Fig. 2). These results suggest that there were slight disturbances in respiratory mechanics early on in the ARDS group. 

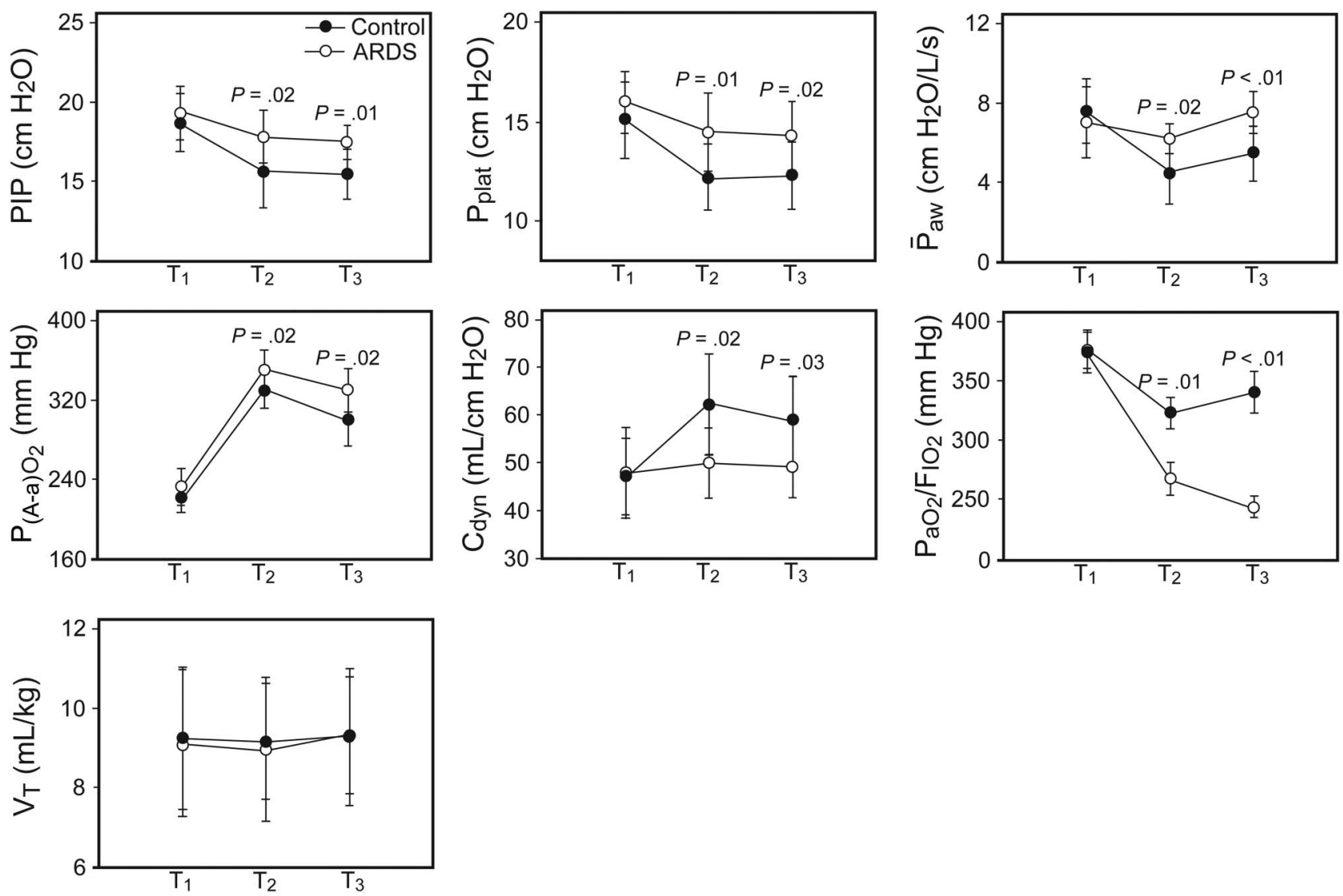

Fig. 2. Peak inspiratory pressure (PIP), mean airway pressure $\left(\bar{P}_{\text {aw }}\right)$, and $P_{(A-a) O_{2}}$ were significantly higher in the ARDS group than in the control group at $\mathrm{T}_{2}\left(2 \mathrm{~h}\right.$ after graft reperfusion) and $\mathrm{T}_{3}(4 \mathrm{~h}$ after graft reperfusion). However, there was no significant difference in tidal volume between the ARDS and control groups. In addition, $\mathrm{P}_{\mathrm{aO}_{2}} / \mathrm{F}_{\mathrm{IO}_{2}}$ and dynamic compliance $\left(\mathrm{C}_{\text {dyn }}\right)$ were significantly lower at $\mathrm{T}_{2}$ and $\mathrm{T}_{3}$ compared with the control group. Data are shown as mean \pm SD.

\section{Inflammatory Mediators in EBC and Serum}

It has been shown that inflammatory mediators play a key role in the pathogenesis of ARDS, but the role of inflammatory mediators in EBC during OLT remains unclear. ${ }^{10}$ In the present study, we found that the levels of TNF- $\alpha$ and IL- 8 in EBC in the ARDS group were significantly higher than in the control group but that the concentrations of IL-10 were much lower in the control group. Similarly, higher TNF- $\alpha$ and IL- 8 concentrations and lower IL-10 concentrations were found in serum in the ARDS group compared with the control group (Figs. 3 and 4).

\section{Mediators of Oxidative Stress in EBC and Serum}

In this study, we found higher levels of MDA, NO, $\mathrm{H}_{2} \mathrm{O}_{2}$, and 8-iso-prostaglandin $\mathrm{F}_{2 \alpha}$ in the ARDS group at $\mathrm{T}_{2}$ and $\mathrm{T}_{3}$ in both EBC and serum compared with the control group. However, the concentration of SOD followed the opposite trend at $\mathrm{T}_{2}$ and $\mathrm{T}_{3}$ (Figs. 3 and 4).

\section{Complications and Outcomes}

The time to extubation, presence of postoperative pulmonary infection, stay in the ICU, and the postoperative stay were all markedly higher or longer in the ARDS group than in the control group (Table 1). Further analysis indicated that the levels of TNF- $\alpha$, IL-8, IL-10 MDA, NO, $\mathrm{H}_{2} \mathrm{O}_{2}$, and 8-iso-prostaglandin $\mathrm{F}_{2 \alpha}$ in EBC at $\mathrm{T}_{2}(\mathrm{r}=0.49, P=.009 ; \mathrm{r}=0.59, P=.001 ; \mathrm{r}=0.53$, $P=.004 ; \mathrm{r}=0.44, P=.018 ; \mathrm{r}=0.49, P=.008$; and $\mathrm{r}=0.45, P=.017$, respectively) and $\mathrm{T}_{3}(\mathrm{r}=$ $0.43, P=.022 ; \mathrm{r}=0.77, P=.004 ; \mathrm{r}=0.39, P=.04$; $\mathrm{r}=0.43, P=.023 ; \mathrm{r}=0.40, P=.037$; and $\mathrm{r}=0.57$, $P=.002$, respectively) all correlated significantly with the time to extubation.

Six subjects suffered from pulmonary infections in the ARDS group after OLT. No subject in the control group suffered from a pulmonary infection. There was no acute renal failure or cardiac insufficiency after surgery. Two subjects died within the first year after discharge: one died 

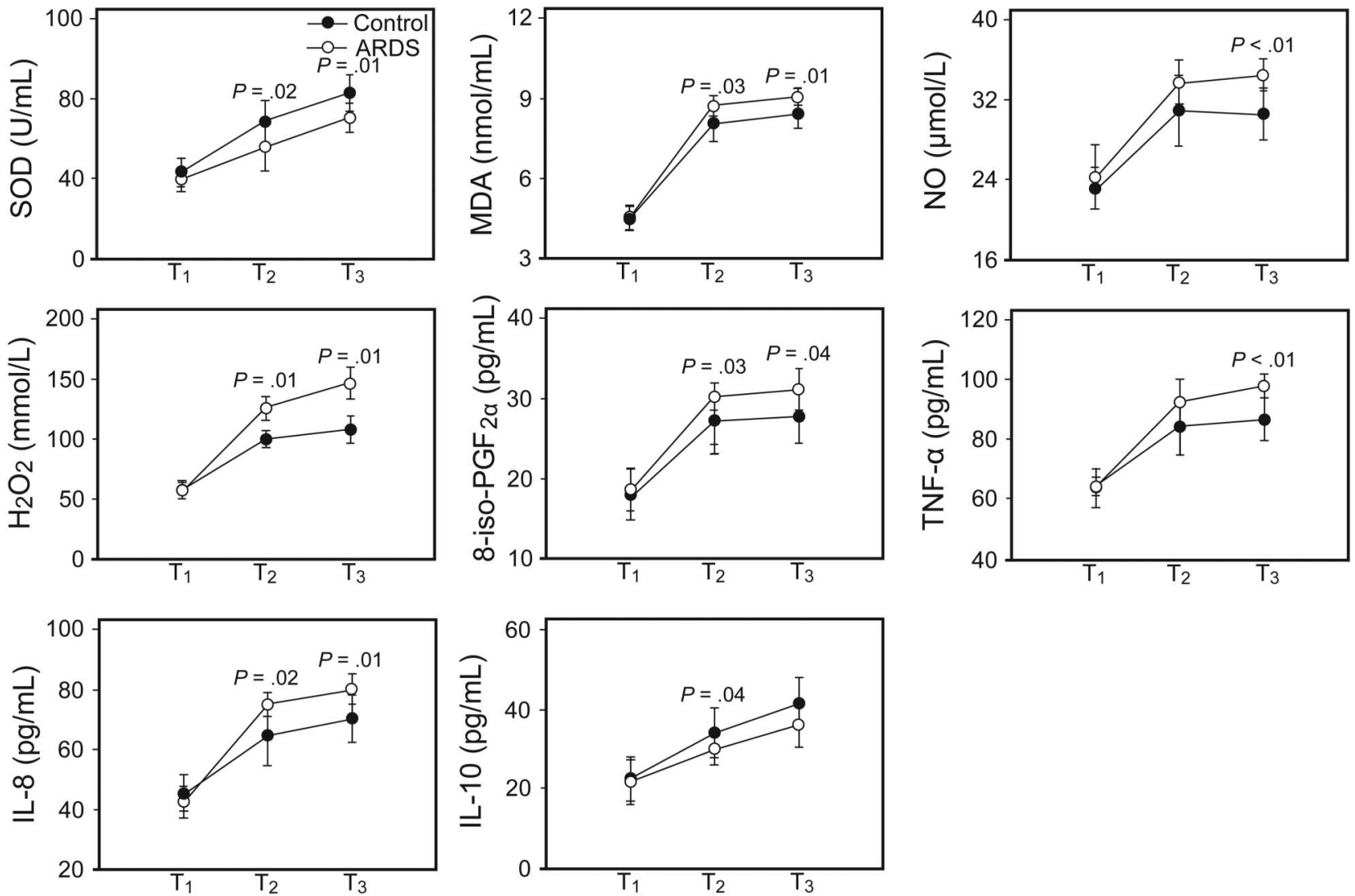

Fig. 3. Levels of tumor necrosis factor- $\alpha$ (TNF- $\alpha$ ) and interleukin (IL)-8 in exhaled breath condensate (EBC) were significantly higher in the ARDS group compared with the control at $\mathrm{T}_{3}$ (4 $\mathrm{h}$ after graft reperfusion), but the concentration of IL-10 was much lower in the ARDS group at $\mathrm{T}_{2}\left(2 \mathrm{~h}\right.$ after graft reperfusion) than in the control group. Higher levels of malondialdehyde (MDA), $\mathrm{H}_{2} \mathrm{O}_{2}$, and 8-iso-prostaglandin $\mathrm{F}_{2 a}$ $\left(8\right.$-iso-PGF $\left.{ }_{2 \alpha}\right)$ and lower concentrations of superoxide dismutase (SOD) were found in EBC in the ARDS group compared with the control group at $T_{2}$ and $T_{3}$. Data are shown as mean $\pm S D$.

of multiple organ failure, and the other died from a recurrence of hepatoma.

\section{Correlation Analysis}

Regression analysis showed the following results: (1) There were no significant correlations between the levels of TNF- $\alpha$, IL-8, IL-10 MDA, NO, $\mathrm{H}_{2} \mathrm{O}_{2}$, SOD, and 8-iso-prostaglandin $\mathrm{F}_{2 \alpha}$ in $\mathrm{EBC}$ and those in serum at $\mathrm{T}_{1}(\mathrm{r}=0.16, P=.38 ; \mathrm{r}=0.19, P=.32 ; \mathrm{r}=0.30$, $P=.11 ; \mathrm{r}=0.15, P=.43 ; \mathrm{r}=0.05, P=.83 ; \mathrm{r}=$ $0.30, P=.11 ; \mathrm{r}=0.03, P=.89$; and $\mathrm{r}=0.22, P=.26$, respectively); (2) the levels of IL-8, IL-10 MDA, $\mathrm{H}_{2} \mathrm{O}_{2}$, and 8-iso-prostaglandin $\mathrm{F}_{2 \alpha}$ in $\mathrm{EBC}$ were significantly correlated with those in serum at $\mathrm{T}_{2}(\mathrm{r}=0.43, P=.03$; $\mathrm{r}=0.51, P=.01 ; \mathrm{r}=0.47, P=.01 ; \mathrm{r}=0.44, P=.01$; and $\mathrm{r}=0.49, P=.01$, respectively); and (3) the levels of TNF- $\alpha$, IL-8 MDA, NO, $\mathrm{H}_{2} \mathrm{O}_{2}$, and 8-iso-prostaglandin $\mathrm{F}_{2 \alpha}$ in $\mathrm{EBC}$ were significantly correlated with those in serum at T3 $(\mathrm{r}=0.67, P<.001 ; \mathrm{r}=0.47, P=.01$; $\mathrm{r}=0.71, P<.001 ; \mathrm{r}=0.59, P<.001 ; \mathrm{r}=0.61$, $P<.001 ;$ and $\mathrm{r}=0.523, P=.005$, respectively).

\section{Receiver Operating Characteristic Curve Analyses}

Figure 5 shows the performances of the biomarkers of inflammation and oxidative stress in diagnosing ARDS at $2 \mathrm{~h}$ after graft reperfusion. The areas under the curve are: 0.88 for MDA, 0.88 for NO, 0.78 for $\mathrm{H}_{2} \mathrm{O}_{2}, 0.84$ for 8-isoprostaglandin $\mathrm{F}_{2 \alpha}, 0.84$ for TNF- $\alpha, 0.94$ for IL-8, 0.81 for SOD, and 0.84 for IL-10 in EBC.

Similarly, Figure 6 shows the performances of the biomarkers of inflammatory and oxidative stress in diagnosing ARDS at $4 \mathrm{~h}$ after liver transplantation. The areas under the curve are: 0.98 for MDA, 0.88 for NO, 0.92 for $\mathrm{H}_{2} \mathrm{O}_{2}, 0.79$ for 8-iso-prostaglandin $\mathrm{F}_{2 \alpha}, 0.95$ for TNF- $\alpha, 0.83$ for IL-8, 0.88 for SOD, and 0.97 for IL-10 in EBC. 

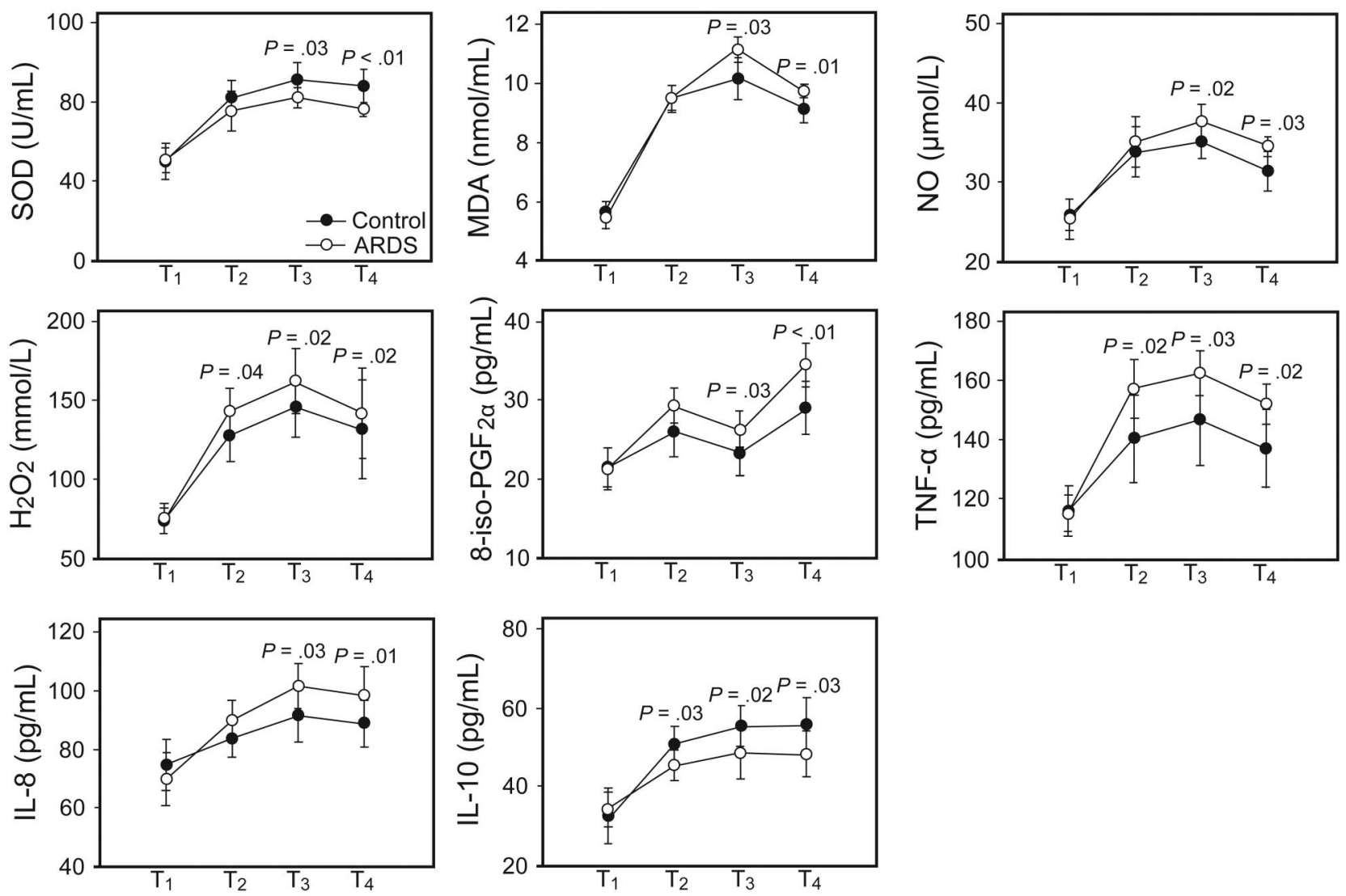

Fig. 4. Higher tumor necrosis factor- $\alpha$ (TNF- $\alpha$ ) and interleukin (IL)- 8 concentrations and lower IL-10 concentrations in serum were found in the ARDS group compared with the control group at $\mathrm{T}_{2}\left(2 \mathrm{~h}\right.$ after graft reperfusion) and $\mathrm{T}_{3}$ ( $4 \mathrm{~h}$ after graft reperfusion). The levels of malondialdehyde (MDA), NO, $\mathrm{H}_{2} \mathrm{O}_{2}$, and 8-iso-prostaglandin $\mathrm{F}_{2 \alpha}\left(8\right.$-iso- $\mathrm{PGF}_{2 \alpha}$ ) in serum were all higher than in the ARDS group at $\mathrm{T}_{2}$ and $T_{3}$. Data are shown as mean \pm SD. SOD $=$ superoxide dismutase.

\section{Discussion}

Over the past several decades, much progress has been made in liver transplantation, but the incidence of postoperative ARDS has not fallen appreciably. ${ }^{11}$ Thus, it has become increasingly important to develop an ability to predict and diagnose ARDS as early as possible. ${ }^{12}$ In this study, we found that levels of inflammatory factors (TNF- $\alpha$ and IL-8) $)^{5}$ and mediators of oxidative stress (MDA, $\mathrm{H}_{2} \mathrm{O}_{2}$, $\mathrm{NO}$, and 8-iso-prostaglandin $\left.\mathrm{F}_{2 \alpha}\right)^{13,14}$ in both $\mathrm{EBC}$ and serum were significantly elevated in subjects with ARDS but that concentrations of IL-10 (an anti-inflammatory cytokine) and SOD (an antioxidant) in EBC and serum both decreased in subjects with ARDS. We also found that all these mediator increases correlate with the incidence of ARDS following OLT and some other poor prognoses. To our knowledge, serum is always affected by fluid infusion or blood loss, and EBC can be obtained directly and noninvasively from the lungs and reflects the true state of the lungs. ${ }^{15}$ Furthermore, our findings suggest that subjects with higher levels of mediators of inflammation and oxi- dative stress had a higher risk of developing pulmonary infection postoperatively and staying longer in the ICU, resulting in a poor prognosis and poor recovery.

Currently, ARDS can be diagnosed by blood gas analysis, bronchoalveolar lavage fluid analysis, and chest $\mathrm{x}$ ray findings. ${ }^{16}$ However, these diagnostic methods either tend to lag behind the clinical picture or are traumatic for patients. Fortunately, noninvasive methods, such as measurements of $\mathrm{EBC}$, have also been used to monitor respiratory disease. ${ }^{17} \mathrm{EBC}$ analysis is a new and noninvasive technology that can detect biochemical markers in the airway and has been reported to be used for the diagnosis of respiratory diseases. To collect EBC samples, multiple custom devices that use a variety of cooling techniques have been used throughout the years. ${ }^{18}$ Effective collection requires a stable collection device that can provide adequate minute ventilation and a low cooling temperature. ${ }^{19}$ In the current study, our EBC collecting device consisted of glass chambers connected to the expiratory limb of the ventilator circuit (Fig. 1). Once an EBC sample is collected, it should be transferred promptly to liquid nitrogen and stored 


\section{Exhaled Breath Condensate Biomarkers and Postoperative ARDS}
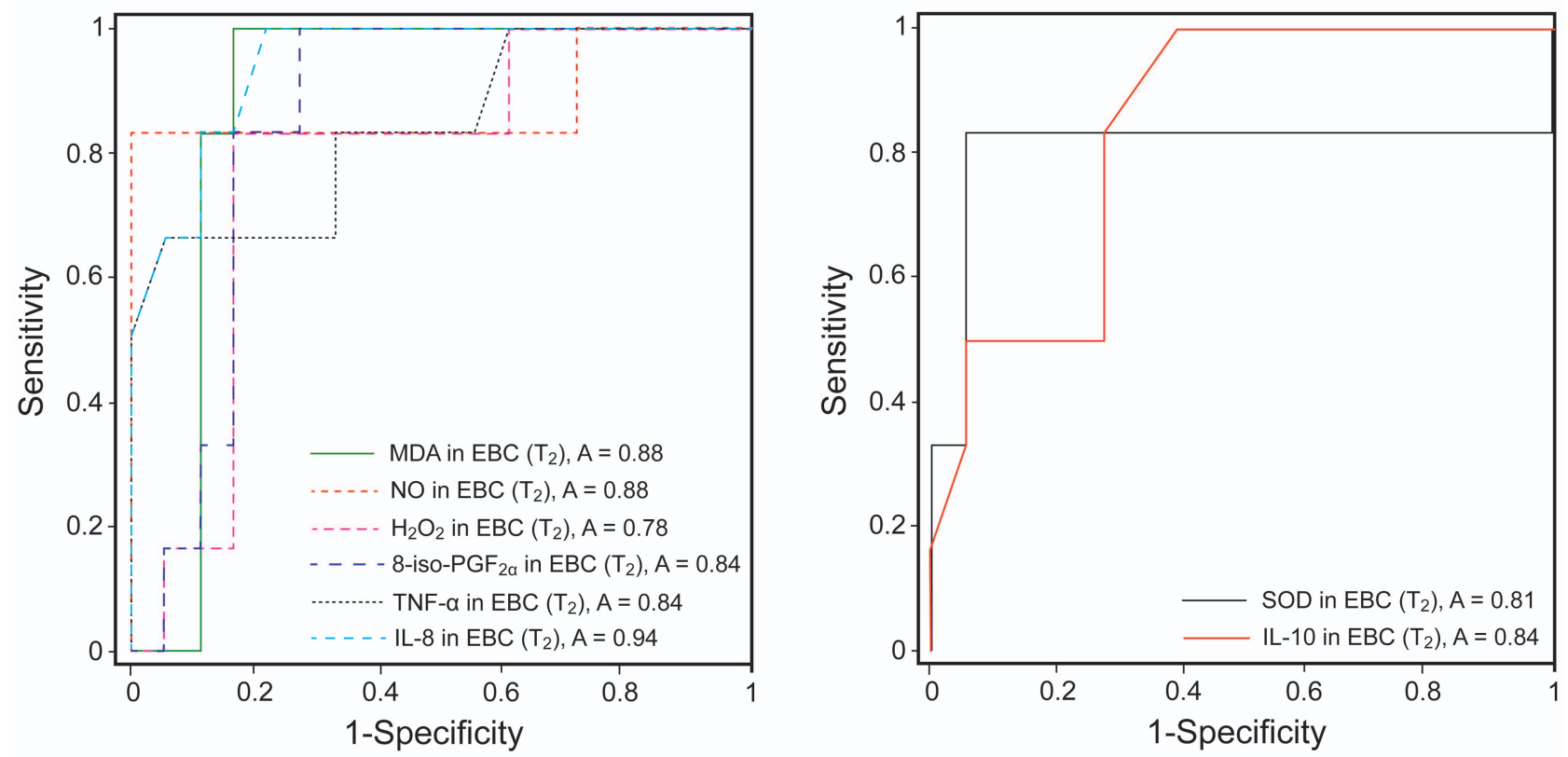

Fig. 5. Receiver operating characteristic curves for biomarker levels in exhaled breath condensate (EBC) at $2 \mathrm{~h}$ after graft reperfusion. The areas under the curve are as follows: 0.88 for malondialdehyde (MDA), 0.88 for NO, 0.78 for $\mathrm{H}_{2} \mathrm{O}_{2}, 0.84$ for 8 -iso-prostaglandin $\mathrm{F}_{2 \alpha}$ (8-iso-PGF ${ }_{2 \alpha}$ ), 0.84 for tumor necrosis factor- $\alpha$ (TNF- $\alpha$ ), 0.94 for interleukin (IL)-8, 0.81 for superoxide dismutase (SOD), and 0.84 for IL-10, in EBC.
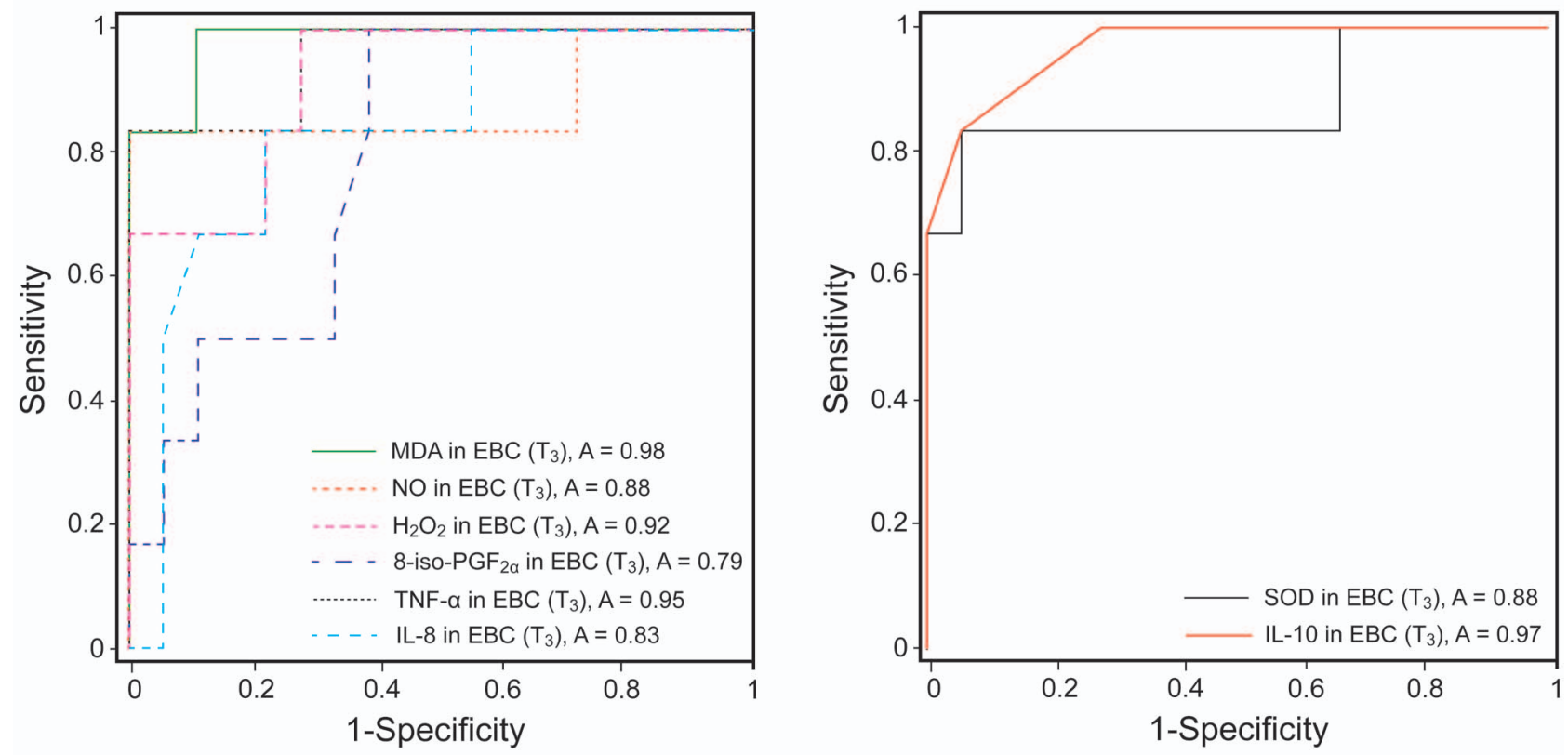

Fig. 6. Receiver operating characteristic curves for biomarker levels in exhaled breath condensate (EBC) at $4 \mathrm{~h}$ after graft reperfusion. The areas under the curve are as follows: 0.98 for malondialdehyde (MDA), 0.88 for NO, 0.92 for $\mathrm{H}_{2} \mathrm{O}_{2}, 0.79$ for 8-iso-prostaglandin $\mathrm{F}_{2 \alpha}$ (8-iso-PGF ${ }_{2 \alpha}$ ), 0.95 for tumor necrosis factor- $\alpha$ (TNF- $\alpha$ ), 0.83 for interleukin (IL)-8, 0.88 for superoxide dismutase (SOD), and 0.97 for IL-10, in EBC.

at $-80^{\circ} \mathrm{C}$ to prevent rapid degradation. Our EBC collection device was also closed to prevent substances in our EBC samples from evaporating.
The pathogenesis of ARDS is complex and includes activation of pulmonary endothelium and macrophages and upregulation of adhesion molecules and cytokines, all of 


\section{Exhaled Breath Condensate Biomarkers and Postoperative ARDS}

which result in a massive sequestration of neutrophils within the pulmonary microvasculature. ${ }^{20}$ These cells release a variety of pro-inflammatory and anti-inflammatory mediators that diffuse into the circulation and other tissues. ${ }^{21}$ To date, nearly all clinical research on inflammatory mediators in OLT has focused on the presence of these mediators in serum to confirm the existence of lung inflammation. ${ }^{22,23}$ However, measurements of these inflammatory mediators in OLT lag behind clinical reality. In this study, we found that the trends of these mediators in EBC were closely related to their trends in serum and that measurements of these mediators in EBC directly reflected the state of the lungs during and after liver transplantation. These findings suggest that EBC collection and evaluation are valuable for the diagnosis of ARDS. The causes of postoperative ARDS after liver transplantation include many aspects, such as fluid overload from crystalloid liquid infusion or massive transfusion, hypotension, sepsis, fast tapering of corticosteroids, gastric aspiration, reperfusion syndrome of the newly implanted liver, intestinal ischemia and reperfusion, and transfusion-related acute lung injury. ${ }^{24}$ Consistent with the findings of some studies, ${ }^{25-27}$ we believed that not only inflammation but also oxidative stress were involved in the mechanism of ARDS. Our findings also indicated higher levels of mediators of inflammation and oxidative stress in EBC, indirectly showing the key role of inflammation and oxidative stress in ARDS after liver transplantation. It has also been suggested that the severity of ARDS could be reduced by actions on several pathways, such as inhibiting the production of oxygen free radicals (such as $\mathrm{H}_{2} \mathrm{O}_{2}$ ) and nitrate radicals (such as $\mathrm{NO}$ ) and reducing pulmonary oxidative damage that is accompanied by increased levels of MDA and decreased levels of SOD. ${ }^{26,27}$ Our results demonstrated that the levels of mediators of oxidative stress detected in EBC followed the same trend as those in serum, which closely correlated with the incidence of ARDS. These results also suggest that pulmonary oxidative stress may have potentially serious consequences and that the levels of mediators of oxidative stress in EBC have the potential to predict the degree of oxidative stress in OLT patients. ${ }^{28}$

Several limitations of this study should be acknowledged. First, although EBC detection is direct, it is not instantaneous, ${ }^{29}$ and this delay could affect the accuracy of results obtained from the analysis of EBC. Second, it is notable that serum TNF- $\alpha$ concentration in this study was 10 times higher than that reported in another study. ${ }^{30} \mathrm{We}$ inferred that the reading of TNF- $\alpha$ was influenced by many factors, including the severity of liver disease, manufacturers of detection devices, and laboratory temperature. Interestingly, the value of TNF- $\alpha$ in this study was similar to that of another study, ${ }^{31}$ which was related to the inflammatory reaction. Third, it seemed that lung compliance improved only in the control group, whereas it remained almost constant in the ARDS group. We learned from another study that removal of the ascites in subjects undergoing liver transplantation tended to improve dynamic lung compliance, ${ }^{32}$ which was consistent with the control group in our study. However, we found that lung compliance decreased after transplantation in the ARDS group, which might suggest worsening respiratory condition. Fourth, there was no mortality related to ARDS in the current study. However, according to the data from another study, ${ }^{8}$ the mortality rate was expected to be markedly higher than ours. After detailed analysis of our results, we found that the ARDS subjects were treated very early and effectively. Furthermore, less bleeding, blood transfusion, and urine volume, as well as shorter operation time, might also correlate with the low mortality. Additionally, no mortality might be due to the small sample size, and the mortality may increase if we enlarge the sample size.

\section{Conclusions}

We showed that analyses of EBC obtained directly from the lungs could be used to generate a noninvasive index to predict the risk of postoperative ARDS after OLT. However, the new technique of EBC has not yet become a routine method of diagnosis for ARDS, and its practical value needs further study.

\section{REFERENCES}

1. Feltracco P, Carollo C, Barbieri S, Pettenuzzo T, Ori C. Early respiratory complications after liver transplantation. World J Gastroenterol 2013;19(48):9271-9281.

2. Jin W, Rong L, Liu Y, Song Y, Li Y, Pan J. Increased claudin-3, -4 and -18 levels in bronchoalveolar lavage fluid reflect severity of acute lung injury. Respirology 2013;18(4):643-651.

3. Caballero S, Martorell A, Escribano A, Belda J. Markers of airway inflammation in the exhaled breath condensate of preschool wheezers. J Investig Allergol Clin Immunol 2013;23(1):7-13.

4. Roca O, Gómez-Ollés S, Cruz MJ, Muñoz X, Griffiths MJ, Masclans JR. Effects of salbutamol on exhaled breath condensate biomarkers in acute lung injury: prospective analysis. Crit Care 2008;12(3):R72.

5. Wen XH, Kong HY, Zhu SM, Xu JH, Huang SQ, Chen QL. Plasma levels of tumor necrotic factor-alpha and interleukin-6, -8 during orthotopic liver transplantation and their relations to postoperative pulmonary complications. Hepatobiliary Pancreat Dis Int 2004;3(1):38-41.

6. Kratzer E, Tian Y, Sarich N, Wu T, Meliton A, Leff A, Birukova AA. Oxidative stress contributes to lung injury and barrier dysfunction via microtubule destabilization. Am J Respir Cell Mol Biol 2012;47(5):688-697.

7. M Van Haperen, PH Van der Voort, RJ Bosman. The oxygenation index compared with the P/F ratio in ALI/ARDS. Crit Care 2012; 16(suppl 1):P91.

8. ARDS Definition Task Force, Ranieri VM, Rubenfeld GD, Thompson BT, Ferguson ND, Caldwell E, et al. Acute respiratory distress syndrome: the Berlin definition. JAMA 2012;307(23):2526-2533.

9. Thomas P, Paratz J, Lipman J. Seated and semi-recumbent positioning of the ventilated intensive care patient: effect on gas exchange, respiratory mechanics and hemodynamics. Heart Lung 2014;43(2): $105-111$. 


\section{Exhaled Breath Condensate Biomarkers and Postoperative ARDS}

10. Solomon R, Sandhu H, Phumeetham S, Gowda KM, Heidemann SM. Detection of inflammation and oxidative lung injury in exhaled breath condensate of rats with acute lung injury due to staphylococcal enterotoxin B. J Breath Res 2013;7(2):026003.

11. Benson AB, Burton JR Jr., Austin GL, Biggins SW, Zimmerman MA, Kam I, et al. Differential effects of plasma and red blood cell transfusions on acute lung injury and infection risk following liver transplantation. Liver Transpl 2011;17(2):149-158.

12. Levitt JE, Calfee CS, Goldstein BA, Vojnik R, Matthay MA. Early acute lung injury: criteria for identifying lung injury prior to the need for positive pressure ventilation. Crit Care Med 2013;41(8):19291937.

13. Lim PS, Chang YM, Thien LM, Wang NP, Yang CC, Chen TT, Hsu WM. 8-iso-prostaglandin F2alpha as a useful clinical biomarker of oxidative stress in ESRD patients. Blood Purif 2002;20(6):537-542.

14. Ho E, Karimi Galougahi K, Liu CC, Bhindi R, Figtree GA. Biological markers of oxidative stress: applications to cardiovascular research and practice. Redox Biol 2013;1(1):483-491.

15. de Broucker V, Hassoun SM, Hulo S, Chérot-Kornobis N, Nevière R, Matran R, et al. Non-invasive collection of exhaled breath condensate in rats: evaluation of $\mathrm{pH}, \mathrm{H}_{2} \mathrm{O}_{2}$ and $\mathrm{NOx}$ in lipopolysaccharide-induced acute lung injury. Vet J 2012;194(2):222-228.

16. Rackley CR, Levitt JE, Zhuo H, Matthay MA, Calfee CS. Clinical evidence of early acute lung injury often precedes the diagnosis of ALI. J Intensive Care Med 2013;28(4):241-246.

17. Romero PV, Rodríguez B, Martínez S, Cañizares R, Sepúlveda D, Manresa F. Analysis of oxidative stress in exhaled breath condensate from patients with severe pulmonary infections. Arch Bronconeumol 2006;42(3):113-119.

18. Davis MD, Montpetit A, Hunt J. Exhaled breath condensate: an overview. Immunol Allergy Clin North Am 2012;32(3):363-375.

19. Carter SR, Davis CS, Kovacs EJ. Exhaled breath condensate collection in the mechanically ventilated patient. Respir Med 2012;106(5): 601-613.

20. Herold S, Gabrielli NM, Vadász I. Novel concepts of acute lung injury and alveolar-capillary barrier dysfunction. Am J Physiol Lung Cell Mol Physiol 2013;305(10):L665-L681.

21. Orfanos SE, Mavrommati I, Korovesi I, Roussos C. Pulmonary endothelium in acute lung injury: from basic science to the critically ill. Intensive Care Med 2004;30(9):1702-1714.
22. Bellamy MC, Galley HF, Webster NR. Changes in inflammatory mediators during orthotopic liver transplantation. Br J Anaesth 1997; 79(3):338-341

23. Zhang A, Chi X, Luo G, Hei Z, Xia H, Luo C, et al. Mast cell stabilization alleviates acute lung injury after orthotopic autologous liver transplantation in rats by downregulating inflammation. PLoS One 2013;8(10):e75262.

24. Li GS, Ye QF, Xia SS, Chen ZS, Zeng FJ, Lin ZB, et al. Acute respiratory distress syndrome after liver transplantation: etiology, prevention and management. Hepatobiliary Pancreat Dis Int 2002; 1(3):330-334

25. Chow CW, Herrera Abreu MT, Suzuki T, Downey GP. Oxidative stress and acute lung injury. Am J Respir Cell Mol Biol 2003;29(4): 427-431.

26. He G, Dong C, Luan Z, McAllan BM, Xu T, Zhao L, Qiao J. Oxygen free radical involvement in acute lung injury induced by $\mathrm{H} 5 \mathrm{~N} 1$ virus in mice. Influenza Other Respir Viruses 2013;7(6):945-953.

27. Lakshminrusimha S, Suresh MV, Knight PR, Gugino SF, Davidson BA, Helinski JD, et al. Role of pulmonary artery reactivity and nitric oxide in injury and inflammation following lung contusion. Shock 2013;39(3):278-285

28. Mumby S, Chung KF, McCreanor JE, Moloney ED, Griffiths MJ, Quinlan GJ. Pro-oxidant iron in exhaled breath condensate: a potential excretory mechanism. Respir Med 2011;105(9):1290-1295.

29. Antus B. Assessment of airway inflammation in chronic obstructive pulmonary disease: biomarkers in exhaled breath condensate. Orv Hetil 2012;153(22):843-851.

30. Shiraki M, Terakura Y, Iwasa J, Shimizu M, Miwa Y, Murakami N, Nagaki M, Moriwaki H. Elevated serum tumor necrosis factor- $\alpha$ and soluble tumor necrosis factor receptors correlate with aberrant energy metabolism in liver cirrhosis. Nutrition 2010;26(3):269-275.

31. Chi XJ, Cai J, Luo CF, Cheng N, Hei ZQ, Li SR, et al. Relationship between the expression of Toll-like receptor 2 and 4 in mononuclear cells and postoperative acute lung injury in orthotopic liver transplantation. Chin Med J (Engl) 2009;122(8):895-899.

32. Shih TH, Yang SC, Chen CL, Wang CH, Cheng KW, Huang CJ, et al. The change of respiratory compliance before and after removal of ascites in living donor liver transplantation. Transplant Proc 2014; 46(3):730-732 